\title{
SPATIOTEMPORAL PATTERN FORMATION IN EARLY DEVELOPMENT: A REVIEW OF PRIMITIVE STREAK FORMATION AND SOMITOGENESIS
}

\author{
S. SCHNELL ${ }^{1}$, K.J. PAINTER ${ }^{2}$, P.K. MAINI ${ }^{1}$ AND H.G. OTHMER ${ }^{2}$
}

\begin{abstract}
The basic body plan of a number of vertebrates results from two processes that occur early in the development of the blastoderm: large scale rearrangements of tissue via a process called gastrulation, and axial subdivision of tissue in a process called somitogenesis. The frst step of gastrulation in avians is formation of the primitive streak, which marks the frst clear manifestation of the anterior-posterior axis. Cell movements that occur through the streak ultimately convert the single layered-blastoderm into a trilaminar blastoderm comprising prospective endodermal, mesodermal and ectodermal tissue. During streak formation a group of cells moves anteriorly as a coherent column from the posterior end of the blastoderm, and as it proceeds other cells stream over the lateral edges of the furrow left behind. The anterior end of the streak is a specialized structure called Hensen's node, which serves as an organizing center for later axis formation and determination of the left-right asymmetry of the body. Soon after the primitive streak forms, Hensen's node regresses towards the tail, leaving the notochord and a pair of segmental plates parallel to the primitive streak in its wake. The posterior end of the segmental plate moves down the cranio-caudal axis with the node, as more cells are added to it by cell division within the plate and by cells entering from the primitive streak. A pair of somites forms from the anterior ends of the two plates at regular intervals. Despite the fact that much is known about the basic biological processes, the mechanisms that underlie the formation of the primitive streak and somitogenesis are still unknown, and elucidating them is one of the major unsolved problems in developmental biology. Mathematical modelling has been a useful tool in this process, as it provides a framework in which to study the outcome of proposed interactions and can make experimentally testable predictions. In this paper we outline the biological background of these processes and review existing models of them.
\end{abstract}

Key words. Primitive streak formation, somitogenesis, theoretical models, mathematical models, Hox genes, c-hairy-1, Notch-Delta genes

1. Introduction. Early vertebrate development is a complex process that involves cell division, cell-cell signaling, cell movement, and cell differentiation. Many adult vertebrates exhibit common structures, but the developmental processes that produce them may or may not be similar. For example, formation of a primitive streak is central to avian, reptilian and mammalian gastrulation, and while it is not present in amphibian blastulae, they contain an analogous structure, called the blastopore. On the other hand, somitogenesis is common to all vertebrates. This review focuses on experimental and theoretical aspects of primitive streak formation and somitogenesis in avian embryogenesis. The chick embryo is a widely-used model system for experimental studies and, as a result, there is a large amount of experimental data. We begin with a brief description of the early events: details of these events can be found in [35], [88], and [50].

The chick embryo develops from a small, disk-shaped blastodisc xoating on top of the yolk. After the egg is fertilized cells divide repeatedly, forming a \footnotetext{
UK.

${ }^{1}$ Centre for Mathematical Biology, Mathematical Institute, Oxford University, Oxford, OX1 3LB,

${ }^{2}$ Department of Mathematics, University of Minnesota,Minneapolis, MN, USA
} 
multicellular stratifed structure called the blastoderm. The period from just prior to laying through several hours afterwards has been subdivided into 14 stages $[31,50]$. Cell division is dominant during stages I - VI, and morphogenetic movements begin during stages VII-X, when cells of the central blastodisc, called the area pellucida ( $c f$. Figure 1), separate from the yolk, producing a hollow region beneath the disc called the subgerminal cavity $[75,99]$. Subsequently some cells from the central blastodisc move into the subgerminal cavity (either actively or passively), and simultaneously the disc expands radially over the yolk. The opaque marginal zone of the blastoderm, known as the area opaca, remains in contact with the yolk and may play an active role in the radial movement (Figure $1 \mathrm{~A})$. The result is that during stages VII-X the central part of the disc changes from a layer 4-6 cells deep to a translucent layer one cell thick called the epiblast. The anterior-posterior axis of the embryo is also determined during these stages [50]. After stage $X$ some cells within the marginal zone migrate posteriorly, and then leave the marginal zone at the posterior marginal zone (PMZ)(Figure 1 B). They spread across the subgerminal cavity beneath the epiblast as a looselyconnected sheet, incorporating islands of cells shed from the blastodisc earlier. By stage XIV this sheet connects with the anterior margin of the disc and forms the hypoblast, and at this stage the blastoderm is bi-layered with the epiblast and hypoblast separated by the blastocoel cavity. Fate maps for cell movements in these stages are available [39].

During hypoblast formation the embryonic shield or Koller's sickle develops at the posterior end of the epiblast (cf Figure 2(a)). This consists of a thickened epiblast [93] comprising primitive streak precursor cells that have migrated to this area by a series of 'polonnaise movements' [105]. The £rst visible sign of gastrulation is formation of the primitive streak, which arises from Koller's sickle at the posterior midline of the blastodisc [52] (Figure 1 C and D). The sickle narrows and the primitive streak moves anteriorly between the epiblast and the hypoblast. The tip of the ingressing streak moves $\sim 60 \%$ of the way across the blastoderm before it stops, and later, regresses. At full primitive streak stage (Hamburger and Hamilton stage 4, [38]) the organizer of the avian embryo, Hensen's node, develops as a bulbous structure at the anterior tip of the streak. The period between the accumulation of cells at the posterior region and full primitive streak is approximately 12 hours. The structure of the blastoderm at this stage is illustrated in Figure 2(b). During the advance of the node, epiblast cells move through the streak and into the interior. Those that migrate through the node form anterior structures, those that migrate through the lateral parts of the primitive streak become endodermal and mesodermal cells, and the remainder constitute the ectoderm. Simultaneously, the area pellucida changes from circular to pear-shaped, narrowing in the posterior portion. The head structure, notochord and somites are laid down during regression of the node, and when regression is complete the embryo is a at trilaminar blastoderm comprising the ectodermal, mesodermal and endodermal layers. These will form various organs during subsequent morphogenesis, in addition to the structures formed during regression. The regressing node and anterior portion of the streak eventually form the tail bud [94]. Re- 


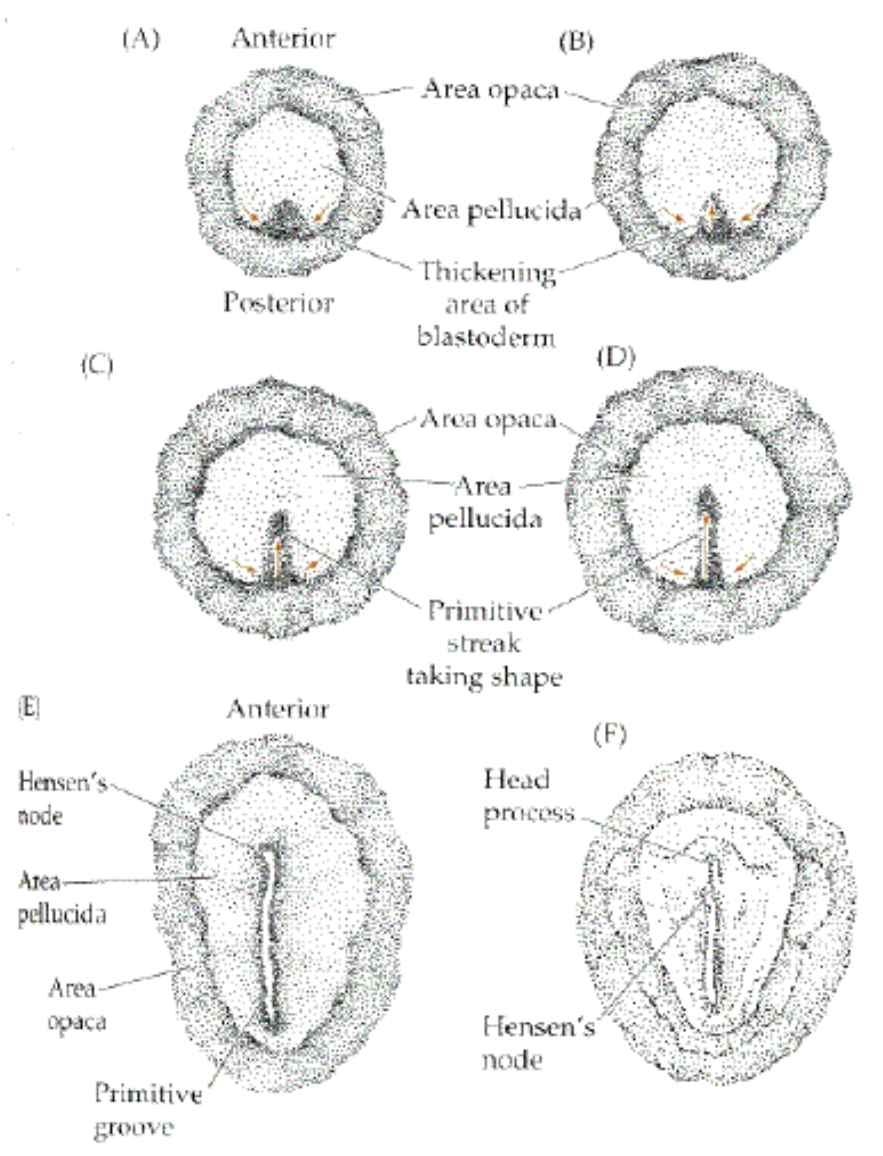

FIG. 1. A schematic of the stages in early development of the chick embryo (A) 3-4 hours postlaying, (B) 5-6 hours, (C) 7-8 hours, (D) 10-12 hours, (E) 15-16 hours, (F) 19-22 hours, . (Reproduced with permission from [35])

gression proceeds on a slower time scale than progression, taking approximately 24 hours for the node to regress after the streak reaches its maximum length of approximately $1.9 \mathrm{~mm}$ [94].

During regression of the primitive streak the neural folds begin to gather at the center of the embryo, and the segmental plates, which are often referred to as paraxial mesoderm or presomitic mesoderm (PSM), separate into blocks of cells known as somites. They form as paired epithelial spheres arranged bilaterally along the anterior-posterior axis and emerge in strict cranio-caudal order [36]. Simultaneously, new cells are incorporated into the PSM from the regression of Hensen's node at the same rate as new somites are formed rostral to the PSM $[16,83]$. Figure 3 is a schematic representation of these early processes. Somites are divided by a £ssure into anterior and posterior halves that differ in their gene 

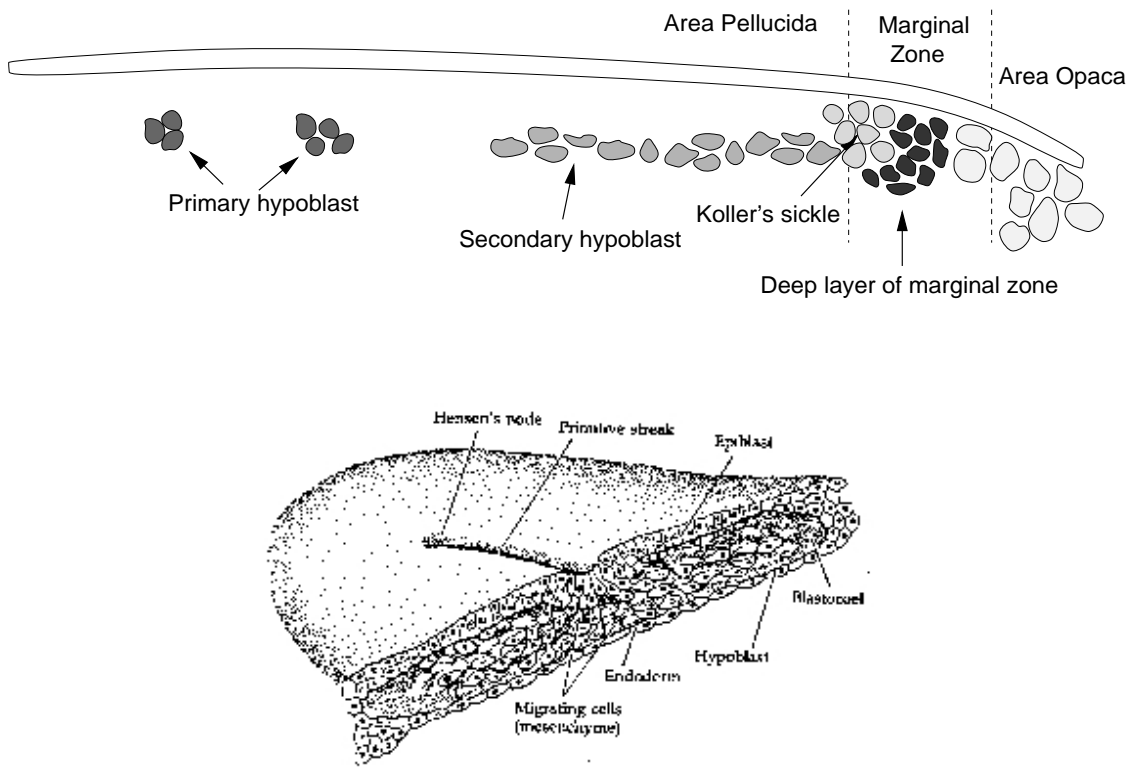

FIG. 2. (a) A schematic cross-section of the blastoderm prior to primitive streak formation. (b) The blastoderm at the stage of maximal streak ingression (Reproduced with permission from [35])

expression and differentiation $[104,36]$.

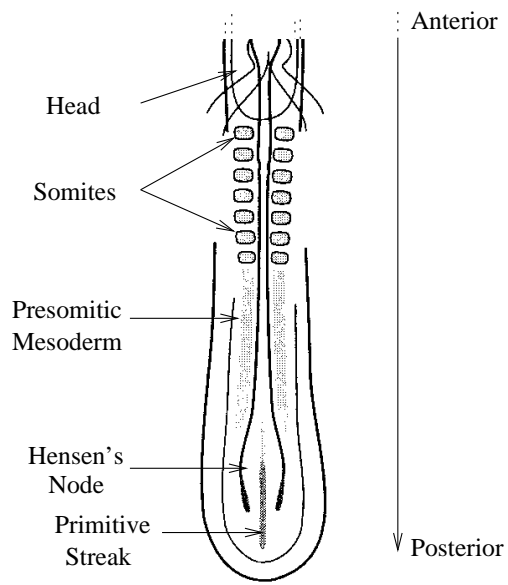

FIG. 3. A schematic diagram illustrating the main structures involved in somitogenesis. Segmentation of the presomitic mesoderm occurs in an anterior-posterior sequence and the time taken for the formation of a somite is approximately 90 minutes in the chick. See text for details. (Redrawn from [10].) 
The formation and differentiation of somites is the result of three distinct morphological events progressing in a strict spatio-temporal order: (1) the prepatterning of the PSM; (2) somite and somitic boundary formation; and (3) the differentiation of a somite into anterior and posterior halves [36]. Several experimental observations confrm these events. Scanning electron microscopy observations [42] and transplantation experiments [49] show that the PSM displays a prepattern prior to segmentation. In addition, Hox and Notch-Delta pathway genes are involved in all these events $[104,25]$. These molecular results suggest the existence of a conserved mechanism for segmentation in protostomes and deuterostomes [61].

The segmental pattern of somites in turn governs the segmental pattern of the peripheral nervous system and determines the shapes and appendage characteristics of the vertebrae. Somites are also the source of cells for muscles, and inquence the metameric distribution of blood vessels. Genetic or/and environmental factors disturbing somitogenesis produce malformations and abnormal development $[117,27,36]$.

Although the sequence of events in early avian development is well documented, less is known about the mechanisms that give rise to primitive streak formation and somitogenesis. A number of theoretical models have been proposed to explain somitogenesis, and while these models are satisfactory in some respects, none can explain the complete set of observations. In the following subsections we present a brief exposition of the current experimental facts on primitive streak formation and somitogenesis. We then describe the theoretical models developed to explain some of these observations.

1.1. Formation of the primitive streak and the organizer. The ability of specifc parts of the embryo to induce a primitive streak and node has been identifed by a number of experiments. In particular, two regions have been tested, the PMZ and Koller's sickle. We should stress that references below to the PMZ may include Koller's sickle, except where stated explicitly.

I. Posterior Marginal Zone (PMZ).

- At stage X, transplants or rotation of the PMZ to lateral or anterior positions can form an ectopic primitive streak; at stage XI the inner region in contact with the PMZ also has the potential to form primitive streak, and at stage XII the PMZ has lost the ability to induce a primitive streak [53]. At both stages X and XI the size of the transplanted fraction is also critical in its capacity to initiate an ectopic axis [30].

- If a fragment of the PMZ is removed and replaced by lateral marginal zone (LMZ) tissue at stage $\mathrm{X}$, a single primitive streak always originates in the normal position, but if the fragment of PMZ is replaced by beads which prevent healing of the wound, then two primitive streaks form [54].

- If donor PMZ tissue is inserted at $90^{\circ}$ to the host PMZ at stage X, a single primitive streak develops at the site of the host PMZ. However, if the host $\mathrm{PMZ}$ is removed two small primitive streaks develop, one at the 
normal site and one at the transplant site. Khaner and Eyal Giladi [54] have also demonstrated that transplantation of a portion of the PMZ into the LMZ of a host embryo induces a second primitive streak to grow at $90^{\circ}$ to the primitive streak growing from the PMZ.

- Any part of the blastoderm, provided it contains a portion of the PMZ and is suffciently large, has the potential to develop a normal embryo. The streak is normally initiated along a radius [96]. When the blastodisc is cut in half, perpendicular to the anterior-posterior axis, the posterior half will form a streak initiated from the posterior margin. The anterior half can also form a streak, which is more likely to be initiated from the LMZ, but it may form from the anterior margin. When the cut is made parallel to the anterior-posterior axis, two streaks form, one on either side of the cut.

- Fate map experiments demonstrate that PMZ tissue has the capacity to induce an ectopic primitive streak without contributing cells to the streak [6]. This suggests that the PMZ may function as an avian equivalent of the Nieuwkoop center [66] - a region of the amphibian blastula that induces an organizer in adjacent cells without contributing to it. The experiments further demonstrate that: (i) PMZ does not give rise to hypoblast but remains stationary; (ii) transplants of quail PMZ (cut to exclude Koller's sickle) to the anterior side of a chick anterior region can induce a primitive streak from the anterior pole in a signifcant number of cases, and grafts to the posterior side of the anterior region results in a high frequency of streaks from the posterior end. In neither case, however, does the graft contribute cells to the streak. These experiments suggest that the PMZ determines the position of the streak.

II. Koller's sickle.

- It is known that Koller's sickle begins to form in the PMZ at stage X, and if cell movement in this area is blocked, no primitive streak is formed [95].

- Transplants of Koller's sickle to lateral portions of host embryos [13, 41, 14] can induce an ectopic primitive streak. In normal development, cells of Koller's sickle contribute to the primitive streak [41].

- Detailed fate mapping of midline cells [6] show that the epiblast above Koller's sickle and Koller's sickle itself both contribute cells to the node and primitive streak. The epiblast above and anterior to Koller's sickle, and cells in the anterior part of Koller's sickle, contribute cells to the node and anterior streak, whereas those cells immediately dorsal to the sickle and in the posterior part of the sickle contribute to the posterior part of the streak. Transplants of quail PMZ cut in a manner to include Koller's sickle (compare with previous item) were able to form a primitive streak when grafted to the anterior-most part of a chick anterior fragment with much greater frequency than when Koller's sickle was excluded. The quail cells were found to contribute to the streak when the graft included Koller's sickle. 
- Grafts of PMZ including the sickle retain the competence to induce a primitive streak at later stages than grafts excluding the sickle [6]. The ability of Koller's sickle alone to induce an ectopic axis is lost by stage XIII, but a large fragment of the PMZ together with Koller's sickle can still induce an ectopic axis [52].

Stimulated in part by the wealth of data unearthed in other model developmental systems, many recent experiments have been directed at discovering the genes regulating development. For example, the Hox gene goosecoid is frst found in a small population of cells corresponding to Koller's sickle [41]. Later this gene characterizes cells of the primitive streak, and expression is highest in cells of Hensen's node and the anterior portion of the streak. Brachyury $(C h-T)$ genes are expressed in forming mesoderm in response to inducing factors and at stage XII in a broad arc in the posterior epiblast. These gene expression patterns suggest that primitive streak formation can be regulated by gradients of organizer genes [5].

The signals involved in streak formation, particularly the transforming growth factors, have also been studied recently. A number of members of the transforming growth factor beta family ( $T G F-\beta$ ) have been shown to induce primitive streak formation. For example, activin has been shown to induce development of axial structures $[65,118,23]$, but it does not have the spatial and temporal distribution expected of an inducer. $c V g l$ expressed in the $\mathrm{PMZ}$ of pre-primitive streak embryos has been shown to induce development of an ectopic primitive streak [91]. The activation of the Wnt proto-oncogene pathway potentiates the activity of activin and $c V g 1$. In contrast, the bone morphogenetic protein-4 (BMP-4) inhibits primitive streak formation [102]. Furthermore, BMP antagonists such as chordin can induce both primitive streak formation and organizer genes.

These experiments suggest that areas of the LMZ can form a primitive streak if they are exposed to fragments of PMZ, but they are inhibited from doing so by neighboring PMZ. Thus cells in the PMZ are already differentiated from those in other parts of the marginal zone and the remainder of the blastoderm when ingression of the primitive streak begins.

Traditionally the blastoderm has been considered homogeneous prior to streak formation, but recent $£$ ndings suggest earlier cell diversity and considerable cell movement in the early epiblast [98]. Canning and Stern [15] identi£ed a subpopulation of cells testing positive for the epitope HNK-1, which is frst expressed on the surface of cells of the PMZ and on those which later form primary hypoblast. Later it is found in the area of streak formation, distributed with a distinct anteriorposterior gradient. A primitive streak does not form when these cells are removed. This has led to the suggestion that HNK-1 cells are the source of streak-derived tissue [98]. The precise role of the epitope itself is not clear, but it may have a role in modulating cell adhesion (see [97] and references therein).

Given the critical role of the organizer in patterning the embryo (for example, formation of the axial structures and left-right asymmetry), it is surprising that in embryos where the node and anterior portion of the streak has been extirpated 
$[37,113,112,84]$, or replaced in reverse orientation [1], a new organizer can be regenerated and development proceeds normally (albeit delayed). In fact, a lateral isolate of the embryo, cut such that both the primitive streak and Hensen's node have been excluded, can reconstitute a primitive streak and organizer [114, 115].

Using labeling techniques, Joubin and Stern [43] have demonstrated that the organizer is not a static population of cells, as was traditionally believed, but is a transitory population of cells that have moved into the node, acquired organizer characteristics (i.e. express specifc organizer genes), and then left the node. It appears that the central third of the primitive streak (axially), characterized by the overlapping expression of $c V g-1$ and $W n t-8 c$, induces the cells anterior to it to acquire organizer characteristics. The organizer prevents neighboring tissue from acquiring organizer status by releasing an inhibitory signal. The issue is confused, however, by the observation of a resident population of cells within the epiblast which remain part of the node during its regression $[89,90,83]$. It has been suggested that this population constitutes stem cells which divide and produce notochord/somite progeny.

1.2. Somitogenesis. During somitogenesis, as in other segmentation processes, the body axis is divided along the anterior-posterior axis into similar repetitive structures formed from the embryonic layers. In insects, such as Drosophila melanogaster, segments are generated by the simultaneous division of the syncitial blastoderm. In other invertebrates such as annelids and crustaceans, and in vertebrates, the mechanism of metamerisation is different; the segments are formed at the cranial end of a multicellular embryo and segmentation propagates caudally [110].

During somitogenesis, continuous inductive interactions with Hensen's node, notochord, neural tube and endoderm are not necessary for somite formation $[7,11,100]$. For example, explants of PSM are able to form somites in the absence of all surrounding structures. Further experiments, in which the PSM is cut into several parts and these parts are rearranged, show that somites do not form. However, if the disrupted PSM is in contact with epithelial structures then somites do form, suggesting that some factor derived from the epithelium may inauence somite formation [69].

Scanning electron microscope images show that the PSM is not a homogeneous tissue. Prior to segmentation, the PSM displays metameric arrangements of groups of cells, named somitomeres by Meier [62], which are evidently the predecessors of somites $[42,36]$. The existence of this prepattern is confrmed in microsurgical experiments $[70,18]$, where isolated parts of the PSM form somites in strict cranio-caudal order some time after their isolation, differentiating into anterior and posterior halves in each somite. The existence of a prepattern is also strongly supported by the periodic pattern of Hox and Notch-Delta gene expression in the PSM [104, 57, 25]. Furthermore, the prepattern of anterior and posterior halves is also established before the formation of a somite [49]. Transplantation experiments reversing the anterior-posterior axis of the PSM demonstrate that the anterior-posterior polarity of the resulting pattern of somites is also reversed, 
so somite halves develop according to their original orientation [2]. In addition, there is a change in the mechanical properties of the cells in the PSM before they differentiate into a somite. There is an increase in cell compaction, and in cell-cell and cell-substratum adhesion, followed by epithelialization [49, 104] of the ball of cells as they form a somite. Several studies suggest that adhesion molecules such as cadherins play a major role in these processes [26, 85, 59]. It should be noted that cell labeling experiments indicate that cells of the PSM can contribute to more than one somite, suggesting that the prepattern of somitomeres does not preclude mixing between the prospective somites [101].

The total number of somites is regulated in an embryo. The Amputated mouse mutant, which is shorter than the wild-type mouse, has the same number of somites, but their somites are considerably smaller than those of the wild-type embryos [32]. However, the number of somites can be altered experimentally [49]. For example, heat shock applied to chick embryos can induce the formation of an extra somite $[106,82]$, or can result in up to four repeated somite anomalies, confned to one or to both rows, separated by relatively constant distances of six to seven normal somites [82]. The repeated anomalies suggest that heat shock affects an oscillatory process within the somite precursors [101].

There appears to be some degree of cell cycle synchrony between cells in the PSM which are destined to segment together to form a somite. The cell cycle synchrony is observed in the early somite two cell cycles after segmentation $[101,81]$. To some extent, cells of the PSM seem to be arranged in order of developmental age, with cells at a given level having relatively synchronous cell cycles. The rostral end of the PSM has an increased mitotic index, which indicates that this region has a high proportion of cells in mitosis [82].

Recently, the study of the expression of the transcriptional factor c-hairy-1 in the PSM of chick embryos has provided molecular evidence for the existence of a segmentation clock [72, 22]. During segmentation, the cells of the PSM go through 12 cycles of $c$-hairy-1 expression before becoming part of a somite, while more cells are continuously incorporated into the posterior end of the PSM. This observation suggests that the segmentation clock controls the time duration of cells in the PSM before they will form part of a somite. During the time taken for one somite to form, the expression of c-hairy-1 sweeps along the PSM in the posterior-anterior direction, narrowing as it propagates (see Figure 4). This wavefront-like expression £nally stops and is maintained in a half somite-sized domain which gives rise to the caudal half of the forming somite. The c-hairy- 1 expression is independent of cell movements and does not result from the propagation of a signal in the plane of the PSM; it is an intrinsic cell autonomous property of this tissue [61, 79]. More recently, studies by McGrew et al. [60] and Forsberg et al. [33] have shown that lunatic fringe (l-fng) gene expression resembles the expression of $c$-hairy- 1 in PSM. In fact, they show that both expressions are coincident and are responding to the same segmentation clock [80]. In Drosophila, it is known that $l$-fng plays an important role in the formation of the wing margin by potentiating Notch activation by Delta and the inhibition of Notch activation by the alternative ligand Serrate $[74,116]$. In $l$-fng mutant mice, 
the formation of somites is disrupted and if a somite forms its anterior-posterior patterning is disturbed $[27,117]$.

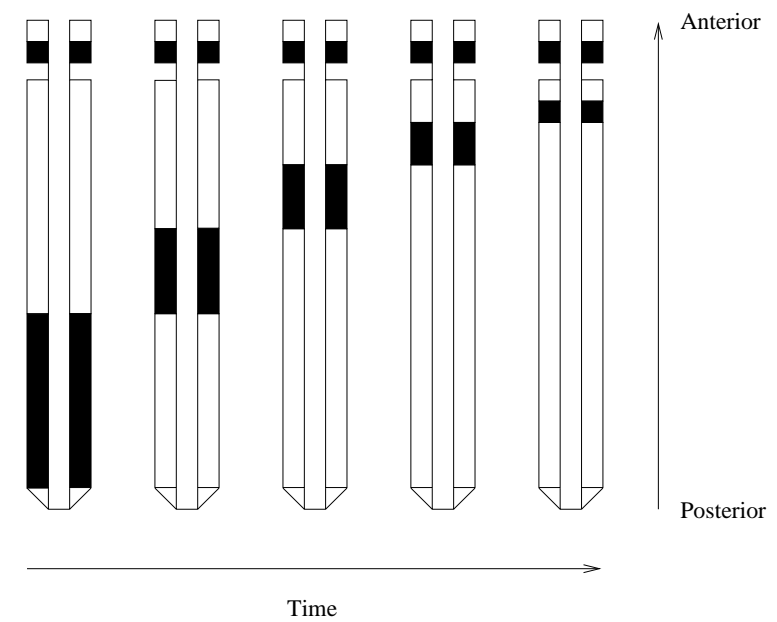

FIG. 4. Schematic illustration of the wave of c-hairy-1 sweeping in the posterior-anterior direction (bottom to top) along the PSM with time (left to right). The shading denotes expression of this factor. It begins as a broad wave but narrows as it moves anteriorly until it Enally correlates with the posterior half of the new forming somite. Then a new wave begins at the posterior margin of the PSM. Similar behavior is observed for lunatic fringe.

Finally, it is important to mention that the principle differentiation pattern of all the somites is very similar. However, during morphogenesis subsequent differentiation forms unique anatomic structures, depending on the position along the anterior-posterior axis. Experiments in chick embryos demonstrate that the positional specifcation of somites occurs early during somitogenesis [55, 20, 21, $19,107,17,12]$. When cervical somites are replaced with somites from the trunk region, rib-like structures develop in the cervical vertebral column of the embryo. When thoracic somites are replaced by cervical somites, embryos do not develop ribs [55]. There is now a large body of experimental work showing that positional specifcation of the PSM requires members of the Hox gene family [57]. Hox gene activation during development correlates with gene position in the Hox complex, a property referred to as colinearity. The spatial and temporal colinearity in the expression of these genes results in unique combinations of Hox genes in defned groups of somites and their derivatives along the anterior-posterior axis $[34,40]$. This led to the suggestion that a Hox code specifes the identity of somites [48, 47]. The role of Hox genes in positional specifcation has been analyzed by interfering with or altering the expression of single Hox genes or by simultaneously perturbing the expression with retinoic acid, which is implicated in the specifcation of the axes during development [103].

2. Questions. Early organization of the avian blastoderm clearly involves a carefully controlled sequence of events. At present, very little is known con- 
cerning the mechanisms regulating this development and here we list some of the major unresolved questions. In the following section we describe some of the theories postulated to explain these processes.

1. How is the posterior site of the embryo determined? Formation of the area pellucida involves a gravity induced directional shedding of cells (posterior to anterior) to form a one-cell thick layer [56]. How is this translated into the structural differences associated with the posterior region (e.g. Koller's sickle, secondary hypoblast formation)?

2. Development of the primary hypoblast involves an apparent dropping of cells in the area pellucida to form isolated islands in the subgerminal cavity [15]. What leads to the early diversifcation of such cells, and how do they separate from the area pellucida? One possibility is to link the diversifcation with the cell cycle, such that at the time of primary hypoblast formation a randomly scattered population in a specifc phase of the cycle experiences a change in its cellular properties, for example adhesion. This change in adhesion may result in such cells being forced from the area pellucida. To test such a hypothesis, it is necessary to construct a discrete cell model which incorporates cell adhesion [73].

3. What controls formation of the secondary hypoblast, and does the hypoblast inquence streak formation? The role of the hypoblast in streak formation is controversial, and earlier experiments in which the hypoblast has been shown to induce streak formation [108, 3, 4] have been challenged by recent experiments [51]. However it is still not known whether the hypoblast is able to exert some inquence over streak formation.

4. What initiates motion and guides the early migration of cells in the lateral regions toward the PMZ? Stern [97] observed migration of a subpopulation of the area pellucida to the posterior marginal zone prior to streak formation and speculated that a chemoattractant is produced at that site. Although collagen-gel assays support this theory, no chemoattractant has been identi£ed.

5. What cues guide elongation and movement of the primitive streak? A simple anterior-posterior gradient of a diffusible morphogen cannot be used for positional information along that axis [53], for if it were the $90^{\circ}$ transplants of the primitive streak would ingress toward the anterior pole rather than along a ray through the center of the disk.

6 . What is the role of cell division in streak formation? Recent results by Wei and Mikawa [109] suggest that a subpopulation of cells in the posterior region may divide in a directional manner to form the primitive streak. It remains to be understood whether this division is essential for streak formation, or if it is simply an associated phenomenon.

7. What mechanisms can account for the fact that the primitive streak maintains its rod-like structure during ingression? Does the primitive streak ingress by convergent extension [46], whereby cells intercalate at the posterior marginal zone and push the primitive streak forward? Are there adhesive differences between cells in the primitive streak and those in the hypoblast and epiblast, or is the structure maintained by chemotactic at- 
traction between cells in the primitive streak? Alternatively, is the streak maintained as a rod by the forces occurring throughout the blastoderm at these stages.

8. There appears to be a gradient within the marginal zone of potential to form a streak, with the posterior being the most capable and the anterior the least. At what stage is this potential determined, and by what mechanisms?

9. The primitive streak seems to inhibit other streaks from forming. What is the nature of this inhibition, and is it confned to act along the marginal zone?

10. The size and age of a blastodisc segment or donor implant are important in determining the site of streak formation. How do the key properties sinvolved change with time?

11. How is the organizer defned, and how are the movements of cells through the organizer to form notochord, head process, paraxial mesoderm, etc., regulated? Recent experiments have revealed that the organizer is a transitory population continuously de£ned by cells in the middle part of the primitive streak [43]. Previous results, however, suggest that there exists a resident population of cells within the organizer that moves back with the node throughout regression. What is the relevance, if any, of this resident population?

12. What mechanisms control regression of the streak/organizer? Does regression of the streak simply occur through the disappearance of anterior cells into axial structures. Does the node regress by being pushed back by cells that are ingressing through it? Ablation of the node results in the regeneration of a new node, yet the new node must regenerate before regression proceeds. Does the static population of cells within the node control the movements of the node during regression?

13. How is the left-right asymmetry established? The earliest indication of left-right asymmetry in the avian embryo occurs with the asymmetric expression of sonic hedgehog (shh) in the avian node [58]. Studies in the mouse have revealed the presence of a nodal quid oow from right to left as a result of unidirectionally rotating cilia on node cells $[67,68]$ and this has been linked with the establishment of the left-right axis. However, no such cilia have been located in the chick, and the cause of left-right asymmetry remains unknown.

14. What regulates the number and size of somites?

15. What determines differentiation into anterior and posterior halves within a somite?

16. What are the differentiation and mechanical properties involved in the epithelialization of somites?

17. What determines the regional specifcation of somites - that is, certain somites form certain structures. What is the precise role of the Hox family in this process and how is it controlled?

18. What drives the segmentation clock? Is there a relation between the cellcycle and the segmentation clock? 
19. What is the precise role of the segmentation clock during somitogenesis?

20. How is the interplay between the segmentation clock and Notch-Delta and related components established?

21. What regulates the refnement of the c-hairy-l and $l$-fng cycles in the forming somite? How do these cycles interact with the segmentation clock?

22. How can the heat shock experiments be explained?

3. Models of streak formation and somitogenesis.

3.1. Formation of the primitive streak. PI. Model of Induction by Gravity: Eyal-Giladi [29] proposed that substances needed for the initiation of primitive streak formation become nonuniformly distributed by gravity while the embryo is tilted, moving from the vegetal pole toward the region that is incorporated into the PMZ. Alternatively, Eyal-Giladi also suggests that these factors can be located under the embryo and shifted toward the posterior by the sliding of the yolk, and could later be found in the PMZ and Koller's sickle. Classic experiments in chick embryos have established that labile anterior-posterior polarity is determined 20 hours after fertilization. During this period there is a critical 2-hour time window where the outer albumen layers are rotated by the uterus while the yolk remains stationary but slightly tilted within a layer of low friction thin albumen [28]. In these experiments, the side of the embryo that is tilted upward during the critical window is defned as posterior. This model is unsatisfactory in some aspects. Little work has been done on this hypothesis due to the dif£culty of obtaining uterine eggs. In addition, this model does not address the ingression and regression of the primitive streak.

PII. Model of Induction by the PMZ: In this model, proposed by Bachvarova [5], the PMZ is considered analogous to the Nieuwkoop Center of the frog embryo, which is the structure responsible for induction during the Erst stages of amphibian development. The PMZ of the chick embryo acts as an extra-embryonic signaling center promoting formation of the primitive streak in the adjoining posterior central disc epiblast. According to the model, factors such as $V g 1$ and Wnt $8 \mathrm{c}$ produced in the PMZ activate organizer genes such as goosecoid in Koller's sickle and chordin in the posterior central-disc epiblast. In turn, chordin suppresses $\mathrm{BMP}$ and this decrease promotes activation of organizer genes in the posterior midline. Lower concentrations of $V g l$ or $T G F-\beta$ factors induce Brachyury-like genes in a broader crescent of posterior central disc epiblast, leading to mesoderm formation. BMP activity from lateral and anterior marginal zone induces epidermis in the adjoining central disc. Finally, the activation of the Wnt pathway in the late uterine and freshly laid egg plays an important role in the asymmetry observed in cells of Koller's sickle and the hypoblast.

This model incorporates several aspects of primitive streak formation. However, as in the previous model it does not address the ingression and regression of the primitive streak. Furthermore, as indicated by Bachvarova [5], many outstanding problems remain with this model. For example, it is not clear if factors such as $V g 1$ are required in normal development. In addition, other factors such 
as $T G F-\beta$ cannot be present and active in early embryos; and little is known about the Wnt pathway.

A mathematical formulation of this model could help understand the outcome of the complex of interactions proposed and make experimentally-testable predictions.

PIII. Chemotaxis Model: Chemotaxis (or haptotaxis) is a plausible mechanism for the observed oriented cell movements both prior to and during primitive streak formation, and this mechanism has been incorporated into a model designed for formation and subsequent maintenance of the streak (though not the determination of the initial site of outgrowth) [71].

The model assumes that there is a specialized subpopulation of cells residing at or close to the posterior marginal zone that both respond to and modulate the level of an attractant. This population serves to mark the site of the primitive streak and guide the movements of elongation and regression. Several cell populations have been identi£ed $[41,99,109]$ as having a role in primitive streak formation. The model does not, however, postulate how other cells ingress through the streak. In Figure 5 we show the pattern of movements predicted on a twodimensional domain. To achieve movement of cells as a rod, rather than a general spreading of cells, it is necessary to choose conditions such that the chemoattractant initially has its highest concentration at the center of the domain (corresponding to the center of the area pellucida) and decreases to zero at the marginal zone. Plausible mechanisms for generating such conditions are given in [71].

The model makes a number of experimentally-testable predictions (Figure 6). Firstly, it predicts that any ectopically induced embryonic axis will develop along radial lines. Secondly, it predicts that disruption of the center of the area pellucida will have a signifcant effect on the morphology of the streak. It also predicts the natural development of an organizer region at the anterior portion of the streak as a region of higher cell density, and demonstrates a decrease in the rate of regression as the streak moves back, in agreement with experimental results [94]. However there is no experimental evidence for chemotactic motion in streak formation, and it is unclear whether the same mechanism that drives propagation of the streak is also responsible for regression. Thus this model simply demonstrates that chemotaxis can produce the observed behavior.

PIV. Cell Division Model: Wei and Mikawa [109] have proposed a model for formation of the streak based on directional cell division. In this model, a specifc subpopulation of cells (localized at stage XII to the epiblast-midline region of the PMZ) undergoes oriented cell division along the anterior-posterior axis to form the Hamburger and Hamilton stage 3 primitive streak. The model is supported by cell marking experiments which demonstrate that the Hamburger and Hamilton stage 3 streak comprises only cells derived from this region, and not cells which have migrated in from lateral regions, as has previously been assumed. Furthermore, cells in the streak were shown to have metaphase chromosome plates (which indicate cleavage direction) perpendicular to the anterior-posterior axis. The calculation, based on the number of cells in the pre-streak region and Ham- 


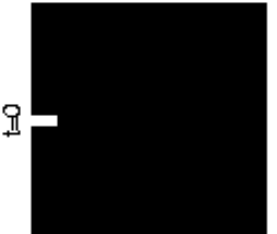

고

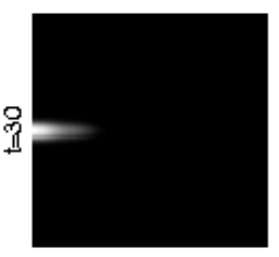

b

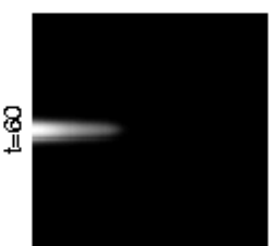

c

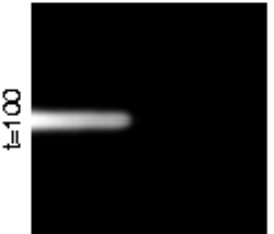

d

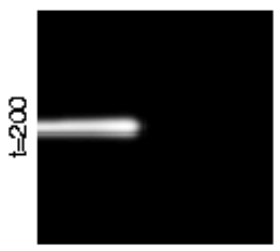

$\theta$

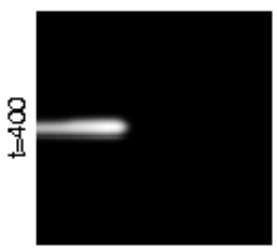

f

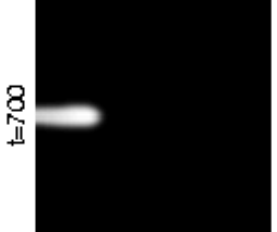

g

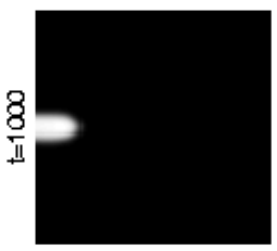

h

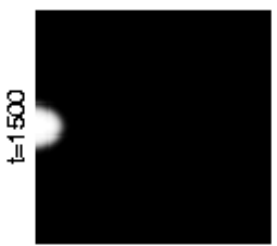

i

FIG. 5. A time sequence showing the cell density for model PIII on a two-dimensional rectangular domain. White represents high cell density, black represents a zero cell density. The results show cell movement across the domain to form a rod which extends approximately half the way across the domain (e). Subsequent development shows a period of reverse movement, which occurs on a slower time scale.

burger and Hamilton stage 3 streak, of a cell cycle time of approximately 4 hours is consistent with the mitotic index for cells of the chick gastrulae.

This model is consistent with the observation that the epiblast portion of the posterior marginal zone contributes to the primitive streak, and with the idea that a PMZ-derived signal induces primitive streak in the adjoining epiblast (see model II above). However, it is not yet clear if directional cell division would be able to induce the streak to form a long straight rod alone, nor is there any suggestion as to how regression of the streak is controlled.

PV. Convergent-Extension Model: Schoenwolf [88] has postulated that primitive streak formation may occur via a convergent-extension mechanism similar to that observed in developing amphibia [44, 45]. In this model, prospective primitive streak cells from either side of the midline would converge at the midline, intercalating with those on the opposite side and thereby producing an elongating primitive streak. This also raises the possibility that regression may occur through a reverse process.

This model is speculative, yet some evidence for it can be found in the gen- 
Simulation Initial Conditions
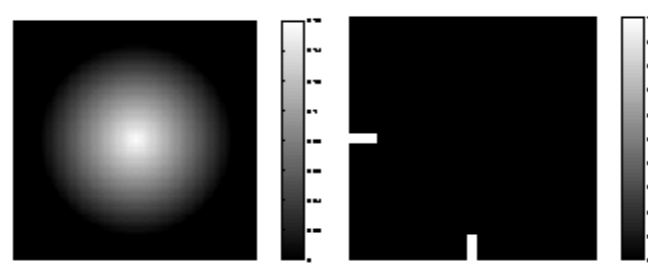

Simulation Initial Conditions
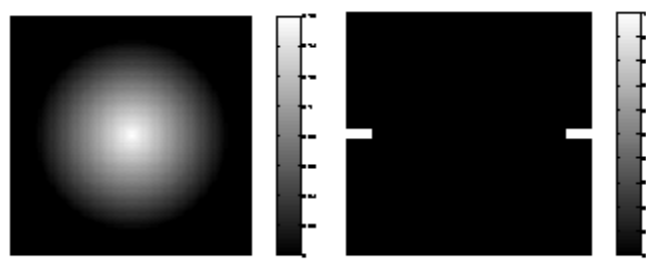

Simulation Initial Conditions
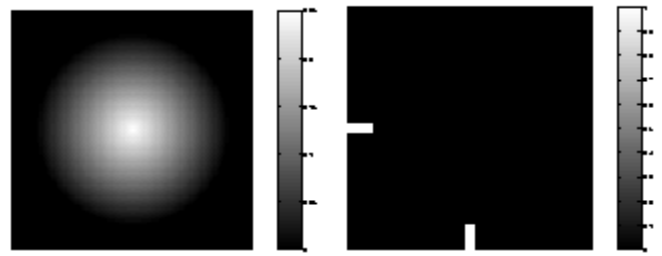

Prediction

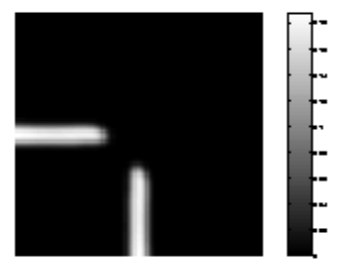

Prediction

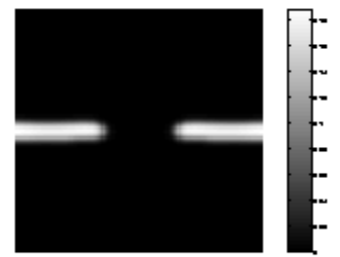

Prediction

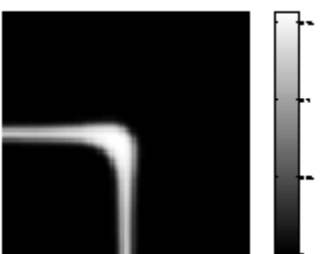

FIG. 6. The time course for the development of an ectopic streak following 'transplantation' in model PIII. When a second population of "able" cells is placed at another point along the marginal zone (top: lateral, middle: anterior), an ectopic streak develops which moves towards the center of the domain. Fairly small changes in model parameters can result in the fusing of these streaks at the anterior ends. In the bottom £gures, this has been effected by increasing the concentration gradient of the chemoattractant.

eral cell movements observed to take place in the epiblast during primitive streak formation [105]. Furthermore, the mechanism could provide an explanation for the change in morphology of the blastoderm from circular to pear-shaped during formation of the streak, as intercalation would result in a streak being driven in both anterior and posterior directions. However the author does not suggest what determines the posterior marginal zone as the site of streak formation, nor what the mechanisms are for guiding cell movement during the convergent-extension process so as to maintain the rod-like morphology of the streak. 
3.2. Somitogenesis. During the last three decades, several models have been proposed to explain the formation of somites $[24,32,8,9,42,49,63,64,76,78$, $77,82,81,87]$. Some of these incorporate the different aspects of somitogenesis previously mentioned, and are satisfactory in many respects. It is important to emphasize that these models cannot explain all the experimental facts presented in section 1.2 , but they do lend insight to many of the observations. The models can be divided into four main categories:

SI. Induction Models: In these models, somite formation is explained in terms of inductive interactions with neighboring tissue [8]. These models are unsatisfactory in many aspects. No single tissue has been shown to induce somite formation. As we previously indicated, somites can be formed in the absence of Hensen's node, notochord, neural tube and endoderm [7,11, 100], but the midline structures are necessary after experimental disruption of the PSM [69].

SII. Prepattern Models: These models postulate that there is a spatially-periodic prepattern present in the PSM before formation of the somites. Bellairs and Veini [11] proposed that somitogenic clusters are generated during PSM formation. Meier [62] suggested that prior to segmentation the PSM displays metameric arrangements of groups of cells, named somitomeres. The observation of the prepattern has been confrmed in microsurgical and transplantation experiments $[70,18,2]$. However, this sort of model does not address the key problems of how the prepattern is set up and how it is maintained and regulated.

SIII. Positional Information Models: These assume that a spatial pattern in chemical morphogen is set up, either via a gradient or a reaction-diffusion mechanism, and this prepattern determines cell differentiation. There are two main models:

1. The wave gradient model was proposed by Wilby and Ede [111] and Flint et al. [32]. This model proposes that regression of Hensen's node creates two strips of paraxial mesoderm, and that cells recruited into them start to synthesize a morphogen. The morphogen concentration increases in the cells until a threshold is reached, at which point an irreversible change from synthesis to destruction of morphogen occurs. The morphogen concentration in these cells falls, establishing a sink relative to cells that are still producing the morphogen. Neighboring cells maintain a morphogen concentration below the threshold, as morphogen diffuses from them into the sink, but cells further back in the paraxial mesoderm exceed the morphogen concentration threshold, and another trough of concentration is formed. Thus, a pattern of alternating peaks and troughs is created, which later gives rise to somites and £ssures respectively. In this model, the size of the somites is determined by either the rate of incorporation of cells into the PSM or the speed of node regression. If the rate of node regression depends on the size of the embryo, then this model can account for the observation that there is regulation of somite number so, for example, in the Amputated mutant mouse embryo, which is only two thirds the normal size, the number of somites formed is still the same as in the normal case. This would be consistent with the assumption that the node regresses more slowly in smaller embryos. However, this model cannot easily explain the observations after the anterior-posterior axis of the PSM 
is reversed. It seems likely that the pattern of morphogen concentration would be severely disrupted during these experiments and the model would not then predict somite formation in the normal way.

2. Meinhardt $[63,64]$ proposed a reaction-diffusion type model, with two cell states $\mathrm{A}$ and $\mathrm{P}$, which locally exclude each other, but stimulate each other over a long range. Cells switch from one state to the other until £nally reaching a stable state. These can lead to a pattern of stable ... APAP ... stripes forming from anterior to posterior. If the transition from, say $\mathrm{P}$ to A, allows a change of segmental specifcation then each AP pair (or segment) will have a more posterior specifcation than its predecessor. Thus a segmental pattern can be generated in which segments have different regional characteristics.

To set up this pattern, Meinhardt proposed two alternative mechanisms, one involving a morphogen gradient in which threshold concentrations of the morphogen are required for successive $\mathrm{P}$ to A transitions, the other involving outgrowth in which new segments are added as the domain grows. Meinhardt's model is in agreement with two observations of Palmeirim et al. [72]: one full cycle of $c$-hairy- 1 oscillation corresponds to the formation of one somite, and c-hairy-1 expression seems to be reminiscent of the spatiotemporal dynamics of one of the autocatalytic substances, because its wavefront expression stops and is maintained in the posterior half of the somites. It is also the only model, to our knowledge, that addresses the regional differences of somites and the anteriorposterior pattern of somites.

This model cannot easily explain the results of the experiment in which an isolated part of the PSM forms normal somites and the experiments that involve reversing the anterior-posterior axis of the PSM. In the former, one would expect any diffusion-based structures to be disrupted by the experiment, while in the latter, the model would predict that somites would form frst in the anterior part of the reversed PSM and somitogenesis would proceed as normal, but in reality they develop according to their original location. One would have to assume that rostral-caudal determination occurs very early and is £xed before isolation or rotation of the PSM. This possible explanation requires more detailed investigation. It is not clear that this scenario is consistent with that envisioned for the $c$-hairy- 1 dynamics. Furthermore this model does not explain the cell-autonomous nature of somite formation which is strongly suggested by the experiments of Palmeirim et al. [72], McGrew et al. [60] and Forsberg et al. [33]. In these experiments, a portion of one side of the PSM is removed but the $c$-hairy- 1 waves propagate in synchrony in both sides of the PSM, including the isolated portion.

As it stands, the model does not appear to explain the heat shock effects which seem to require a link between cell fate and cell cycle. Such a link is not apparent in this model.

IV. Clock or Oscillator Models: There are a number of models along these lines:

1. Cooke and Zeeman [24] were the £rst to propose he exisitence of a cellular oscillator, which they assumed interacts with a progressing wave of cell determination travelling along the anterior-posterior axis of the PSM. This model, known 
as the clock and wavefront model, is able to explain the control of somite number [92], but is contradicted by the results of the experiments which reverse the anterior-posterior polarity of the PSM, because, as in PIII, this model would predict that segmentation should continue in the anterior-posterior direction without disturbance. To be consistent with the observation of the repetitive anomalies observed after the single heat shock experiments $[82,81,101]$ this model would have to additionally assume that the cellular oscillator was closely linked to the cell cycle. The model does not address the formation of the anterior and posterior halves of a somite.

2. Stern et al. [101] proposed that the cell cycle plays the role of the oscillator. This cell cycle model relies on an intracellular oscillator that controls cell division and interacts with a kinematic wave which produces a signal that recruits other cells in the vicinity shortly before segmentation [49, 101, 81]. It explains the periodic anomalies of the heat shock experiments, the cell cycle synchrony observed in the PSM, as well as the isolation and transplantation experiments. This model addresses pattern formation at the cellular level and therefore does not address molecular issues such as the oscillations of $c$-hairy- 1 and its pattern in the PSM. A direct link between this model and the $c$-hairy- 1 oscillations is not obvious, because in chick embryos, the period of the cell cycle in the PSM is 9 hours while the period of the oscillations is only 90 minutes [72]. Furthermore, heat shock experiments in zebra£sh embryos show that the periodic unit of somite defect (four normally formed somite + one abnormally formed), which correspond to 2.5 hours, does not match the overall cell cycle length (4 hours). This suggests that the proposed relationship between segmentation clock and cell cycle in vertebrates should be re-evaluated [86].

3. In a similar model to the one above, Polezhaev [76, 78, 77] proposed that a wave of cell determination moves along the PSM causing cell differentiation in a particular phase of the cell cycle, resulting in these cells secreting an inhibitor which impedes the differentiation of other cells. This model can explain the results of the heat shock experiments, is consistent with the observations of the isolation and transplantation experiments, and the epithelialization observed just before overt segmentation [49, 104]. However, as in the previous model, this model does not address events at the molecular level, nor does it address the formation of the anterior and posterior halves. To explain the regulation of somite number [49] one would have to assume that the cell determination wave moved at different rates (as in PIII 1).

4. Recently, Schnell and Maini [87] have proposed a clock and induction model in which, as a group of cells destined to form a somite traverses the PSM, cells undergo a series of $l$-fng expression pulses, followed by a longer £nal pulse which will remain at the posterior half of the newly forming somite. l-fng expression synthesizes a protein associated with the cell membrane, which increases its membrane levels in a ratchet-like fashion proportional to the segmentation clock oscillations experienced. The formation of a somite is then assumed to be triggered at a threshold level of 1-fng protein. Elements of the Notch-Delta pathway associated 
with $l$-fng would allow the formation of a somite boundary and anterior-posterior pattern, through an induction mechanism. This model is consistent with the rhythmical expression of $c$-hairy- 1 and $l$-fng and the expression of the Notch-Delta pathway genes in PSM. The model can explain the isolation and transplantation experiments, and the heat shock defects. However, it cannot explain the cell cycle synchronization or epithelialization.

4. Discussion. Building the early embryo involves an architectural challenge that higher organisms have addressed through two processes that occur in early development: large scale rearrangements of tissue via a process called gastrulation, and the axial subdivision of tissue in a process called somitogenesis. Remarkably, somitogenesis has many elements in common with limb development. In fact both of these phenomena can be considered as examples of segmentation. For example, in limb development the anterior-posterior specifcation of digit elements (see, Dillon, this volume) is determined by the Hox genes, and differentiation and boundary formation is determined by the Notch-Delta pathway, as in somitogenesis.

In this paper, we have reviewed the theoretical and mathematical models developed to explain primitive streak formation and somitogenesis. Most of these models have been designed to explain particular aspects of these processes and are successful in doing so. In our critique of previous models, we have compared the models only with the experimental results that are widely accepted and which address the gross mechanisms of primitive streak formation and somitogenesis. As the models stand at present, none of them can easily explain all of these experimental observations. It should be noted that the majority of these models were developed before the discovery of the molecular evidence for the control of primitive streak formation and somitogenesis and are based on cell and tissue level observations.

A challenging future problem for theoretical and mathematical modelling will involve linking the pattern formation mechanisms at the cellular level with the molecular control of cell properties. In Section 2 we listed 22 key questions connected with the problems of primitive streak formation and somitogenesis. The reader will note that the models presented in Section 3 addressed only a small fraction of these.

Acknowledgments. This research (SS) has been funded by José Gregorio Hernández and ORS Awards, CONICIT(Venezuela) and a Lord Miles Senior Scholarship in Science. K. Painter and H. G. Othmer are supported in part by grant GM29123 from the National Institutes of Health.

We thank Daragh Mcinerney for helping with Figure 3 and Paul Kulesa for helpful comments on the manuscript.

\section{REFERENCES}

[1] M. ABERCROMBIE, The effects of antero-posterior reversal of lengths of the primitive streak in the, Phil. Trans. Roy. Soc. Lond. B., 234 (1950), pp. 317-338. 
[2] H. AоYама AND K. As Amoto, Determination of somite cells: Independence of cell differentiation and morphogenesis, Development, 104 (1988), pp. 15-28.

[3] Y. AZAR AND H. EYAL-GILADI, Marginal zone cells, the primitive streak inducing component of the primary hypoblast in the chick., J. Embryol. Exp. Morphol., 52 (1979), pp. 79-88.

[4] - Interaction of epiblast and hypoblast in the formation of the primitive streak and the embryonic axis in the chick, as revealed by hypoblast rotation experiments., J. Embryol. Exp. Morphol., 61 (1981), pp. 133-144.

[5] R. BACHVAROVA, Establishment of anterior-posterior polarity in avian embryos, Curr. Opin. Gen. Dev., 9 (1999), pp. 411-416.

[6] R. BachVarova, I. SKromme, AND C. D. STERn, Induction of primitive streak and hensen's node by the posterior marginal zone in the early chick embryo, Development, 125 (1998), pp. 3521-3534.

[7] R. BELlairs, The development of somites in the chick embryo, J. Embryol. Exp. Morph., 11 (1963), pp. 697-714.

[8] — The segmentation of somites in the chick embryo, Bull. Zool., 47 (1980), pp. 245-252.

[9] R. Bellairs, D. A. Ede, AND J. W. Lash, eds., Somites in Developing Embryos, Plenum Press, New York, NY, USA; London, UK, 1986.

[10] R. Bellairs AND M. Osmond, The Atlas of Chick Development, Academic Press, London, 1998.

[11] R. BEllairs AND M. VEINI, An experimental analysis of somite segmentation in the chick embryo., J. Embryol. Exp. Morph., 55 (1980), pp. 93-108.

[12] J. Butler, E. Cosmos, AND P. CAuWenbergs, Positional signals: Evidence for a possible role in muscle £bre-type patterning of the embryonic avian limb, Development, 102 (1988), pp. 763-772.

[13] M. CAllebaut AND E. V. NUETEN, Rauber's (koller's) sickle: the early gastrulation organizer of the avian blastoderm., Eur. J. Morph., 32 (1994), pp. 35-48.

[14] M. Callebaut, E. van Nueten, F. Harrisson, L. van Nassauw, A. Schrevens, AND H. BORTIER, Avian gastrulation and neurulation are not impaired by the removal of the marginal zone at the unincubated blastoderm stage, Eur. J. Morphol., 35 (1997), pp. 69-77.

[15] D. CANNING AND C. STERN, Changes in the expression of the carbohydrate epitope hnk1 associated with mesoderm induction in the chick embryo., Development, 104 (1988), pp. 643-655.

[16] M. Catala, M.-A. Teillet, And N. M. L. Douarin, Organization and development of the tail bud analyzed with the quail-chick chimera system, Mech. Dev., 51 (1995), pp. 51-65.

[17] K. Chada, J. Magram, And F. Constantini, An embryonic pattern of expression of a human fetal globin gene in transgenic mice, Nature, 319 (1986), pp. 685-689.

[18] E. A. G. ChernofF AND S. R. HILFER, Calcium dependence and contraction in somite formation, Tiss. Cell., 14 (1982), pp. 435-449.

[19] A. ChEVAllier, Role of the somitic mesoderm in the development of the thorax in bird embryos. II. Origin of thoracic and appendicular musculature, J. Embryol. Exp. Morphol., 49 (1979), pp. 73-88.

[20] A. Chevallier, M. KIEny, AND A. Mauger, Limb-somite relationship: origin of the limb musculature, Journal of Embryology and Experimental Morphology, 41 (1977), pp. 245-258.

[21] - Limb-somite relationship: Effects of removal of somitic mesoderm on the wing musculature, J. Embryol. Exp. Morph., 43 (1978), pp. 263-278.

[22] J. CoOKE, A gene that resuscitates a theory - somitogenesis and a molecular oscillator, Trends in Genetics (Personal edition), 14 (1998), pp. 85-88.

[23] J. COOKE, S. TAKADA, AND A. MCMAHON, Experimental control of axial pattern in the chick blastoderm by local expression of wht and activin: the role of hnk-1 positive cells., Dev. Biol., 164 (1994), pp. 513-527.

[24] J. COOKE AND E. C. ZEEMAN, A clock and wavefront model for control of the number of repeated structures during animal morphogenesis, Journal of Theoretical Biology, 58 
(1976), pp. 455-476.

[25] I. Del Barco Barrantes, A. J. Elia, K. WÜnsch, M. H. De Angelis, T. W. MaK, J. Rossant, R. A. Conlon, A. Gossler, and J. L. DE LA POMPA, Interaction between notch signalling and lunatic fringe during somite boundary formation in the mouse, Curr. Biol., 9 (1999), pp. 470-480.

[26] J. Duband, S. Dufour, K. Hatta, M. Takeichi, G. M. Edelman, and J. P. Thiery, Adhesion molecules during somitogenesis in the avian embryo, J. Cell Biol., 104 (1987), pp. 1361-1374.

[27] Y. EvRard, Y. Lun, A. Aulehla, L. Gan, ANd R. L. Johnson, lunatic fringe is an essential mediator of somite segmentation and patterning, Nature, 394 (1998), pp. $377-$ 381.

[28] H. EYAL-GILADI, Gradual establishment of cell commitments during the early states of chick development, Cell Differ., 14 (1984), pp. 245-255.

[29] _ Establishment of the axis in chordates: facts and speculations, Development, 124 (1997), pp. 2285-2296.

[30] H. EYAL-GILADI AND O. KHANER, The chick's marginal zone and primitive streak formation, Dev. Biol., 134 (1989), pp. 215-221.

[31] H. EYAL-GILADI AND S. KOCHAV, From cleavage to primitive streak formation: a complementary normal table and a new look at the Erst stages of the development of the chick. i. general morphology, Dev. Biol., 49 (1976), pp. 321-337.

[32] O. P. Flint, D. A. EDE, O. K. WILBY, AND J. PROCTOR, Control of somite number in normal and Amputated mutant mouse embryos: an experimental and a theoretical analysis, Journal of Embryology and Experimental Morphology, 45 (1978), pp. 189-202.

[33] H. ForsBERG, F. CROZET, AND N. A. BROWN, Waves of mouse lunatic fringe expression, in four-hour cycles at two-hour intervals, precede somite boundary formation., Curr. Biol., 8 (1998), pp. 1027-1030.

[34] S. J. GAUNT, Mouse homeobox gene transcripts occupy different but overlapping domains in embryonic germ layers and organs: A comparison of Hox-3.1 and Hox-1.5, Development (Cambridge), 103 (1988), pp. 135-144.

[35] S. F. GilberT, Developmental Biology, Sinauer Associates, ffth ed., 1997.

[36] A. Gossler And M. Hrabe De Angelis, Somitogenesis, in Curr. Topics in Dev. Biol., vol. 38, Academic Press, 1998, pp. 225-287. Jackson Laboratory, Bar Harbor, Maine 04609, USA.

[37] C. GRABOWSKI, The effects of the excision of hensen's node on the early development of the chick embryo, J. Exp. Zool., 133 (1956), pp. 301-344.

[38] V. Hamburger AND H. Hamilton, A series of normal stages in the development of the chick embryo.

[39] Y. HATADA AND C. D. STERN, A fate map of the epiblast of the early chick embryo, Development, 120 (1994), pp. 2879-2889.

[40] P. W. H. Holland AND B. L. M. Hogan, Expression of homeo box genes during development: A review, Genes. Dev., 2 (1988), pp. 773-782.

[41] J. Izpisua-Belmonte, E. D. Robertis, K. Storey, And C. Stern, The homeobox gene goosecoid and the origin of organizer cells in the early chick blastoderm., Cell., 74 (1993), pp. 645-659.

[42] A. JACOBSON AND S. MeIER, Somites in Developing Embryos, vol. 118 of NATO ASI series. Series A, Life sciences, New York: Plenum Press., 1986, ch. Somitomeres: The primordial body segments, pp. 1-16.

[43] K. JOUBIN AND C. STERN, Molecular interactions continuously defne the organizer during cell movements of gastrulation, Cell, 98 (1999), pp. 559-571.

[44] R. KelleR, Vital dye mapping of the gastrula and neurula of xenopus laevis. i. prospective areas and morphogenetic movements of the superfcial layer, Dev. Biol., 42 (1975), pp. 222-241.

[45] - The cellular basis of epiboly: An sem study of deep cell rearrangement during gastrulation in xenopus laevis, J. Embryol. Exp. Morphol., 60 (1980), pp. 201-234.

[46] R. Keller, J. Shin, And P. Wilson, Cell Motility, Control, and Function of Convergence and Extension During Gastrulation in Xenopus, in Gastrulation: Movements, Patterns, 
and Molecules, W. C. R. Keller and F. Griffen, eds., Plenum Press, New York, NY, USA; London, UK, 1991.

[47] M. KESSEL, Respecifcation of vertebral identities by retinoic acid, Development (Cambridge), 115 (1992), pp. 487-501.

[48] M. KESSEL AND P. GRUSS, Homeotic transformations of murine prevertebrae and concommitant alteration of Hox codes induced by retinoic acid, Cell, 67 (1991), pp. 89-104.

[49] R. J. Keynes And C. D. STERn, Mechanisms of vertebrate segmentation, Development (Cambridge), 103 (1988), pp. 413-429.

[50] O. KHANER, Axis determination in the avian embryo, Curr. Topics in Dev. Biol., 28 (1993), pp. $155-180$

[51] - The rotated hypoblast of the chicken embryo does not initiate an ectopic axis in the epiblast, Proc. Nat. Acad. Sci. USA, 92 (1995), pp. 10733-10737.

[52] - The ability to initiate an axis in the avian blastula is concentrated mainly at a posterior site., Dev Biol, 194 (1998), pp. 257-266. Department of Cell and Animal Biology, Hebrew University, Jerusalem, Israel.

[53] O. KHANER AND H. EYAL-GILADI, The embryo forming potency of the posterior marginal zone in stage x through xii of the chick., Dev. Biol., 115 (1986), pp. 275-281.

[54] - The chick's marginal zone and primitive streak formation. I Coordinative effect of induction and inhibition, Developmental Biology, 134 (1989), pp. 206-214.

[55] M. Kieny, A. Mauger, And P. Sengel, Early regionalization of somite mesoderm as studied by the development of axil skeleton of the chick embryo, Dev. Biol., 28 (1972), pp. 142-161.

[56] S. KoChaV AND H. EYAL-GILADI, Bilateral symmetry in chick embryo, determination by gravity, Science, 171 (1971), pp. 1027-1029.

[57] R. KRUMLAUF, Hox genes in vertebrate development, Cell, 78 (1994), pp. 191-201.

[58] M. Levin, Left-right asymmetry and the chick embryo, Sem. Cell. Dev. Biol., (1998).

[59] K. Linask, C. Ludwig, M. D. Hang, X. Liu, and K. K. G. L. Radice, NCadherin/Catenin-mediated morphoregulation of somite formation, Dev. Biol., 202 (1998), pp. 85-102.

[60] M. McGrew, J. Dale, S. Fraboulet, And O. Pourquié, The lunatic fringe gene is a target of the molecular clock linked to somite segmentation in avian embryos, Curr. Biol., 8 (1998), pp. 979-982.

[61] M. J. MCGREW AND O. PouRQuIE, Somitogenesis: segmenting a vertebrate, Current opinion in genetics and development, 8 (1998), pp. 487-493.

[62] S. MEIER, Development of the chick embryo mesoblast: Formation of the embryonic axis and establishment of the metameric pattern, Dev. Biol., 73 (1979), pp. 24-45.

[63] H. MeInhardt, Models of Biological Pattern Formation, Academic Press, New York, USA, 1982.

[64] - Somites in Developing Embryos, vol. 118 of NATO ASI series. Series A, Life sciences, New York: Plenum Press., 1986, ch. Models of segmentation, pp. 179-189.

[65] E. MITRANI AND Y. SHIMONI, Induction by soluble factors of organized axial structures in chick epiblasts, Science, 247 (1990), pp. 1092-1094.

[66] P. NiEUWKOOP, Origin and establishment of embryonic polar axes in amphibian development, Curr. Topics Dev. Biol., 11 (1977), pp. 115-132.

[67] S. Nonaka, Y. TAnaka, Y. OKada, S. TAKeda, A. Harada, Y. Kanai, M. Kido, AND N. HIROKAWA, Randomization of left-right asymmetry due to loss of nodal cilia generating leftward aow of extraembryonic auid lacking kif3b motor protein, Cell, 95 (1998), pp. 829-837.

[68] Y. OKada, S. Nonaka, Y. TANaka, Y. SAiJoh, H. Hamada, AND N. Hirokawa, Abnormal nodal aow precedes situs inversus in iv and inv mice, Molecular Cell, 4 (1999), pp. $459-468$

[69] D.-J. PACKARD, R. ZHENG, AND D. C. TURNER, Somite pattern regulation in the avian segmental plate mesoderm, Development, 117 (1993), pp. 779-791.

[70] D. S.-J. PACKARD AND A. G. JACOBSON, The in auence of axial structures on chick somite formation, Dev. Biol., 53 (1976), pp. 36-48.

[71] K. J. PAinter, P. K. MAini, And H. G. Othmer, A chemotactic model for the advance 
and retreat of the primitive streak in avian development, Bull. Math. Biol., 62 (2000). To appear.

[72] I. Palmeirim, D. Henrique, D. Ish-Horowicz, And O. Pourquie, Avian hairy gene expression identifes a molecular clock linked to vertbrate segmentation and somitogenesis, Cell, 91 (1997), pp. 639-648.

[73] E. Palsson And H. G. OThMer, A model for individual and collective cell movement in dictyostelium discoideum, Proc. Nat. Acad. Sci, (2000). Submitted.

[74] V. Panin, V. Papayannopoulos, R. Wilson, And K. D. IRVine, Fringe modulates notch-ligand interactions, Nature, 387 (1997), pp. 908-912.

[75] P. PENNER AND I. BRICK, Acetylcholinesterase and polyingression in the epiblast of the primitive streak chick embryo., Roux's Arch. Dev. Biol., 193 (1984), pp. 234-241.

[76] A. A. PolezhaEv, A mathematical model of the mechanism of vertebrate somitic segmentation, Journal of Theoretical Biology, (1992).

[77] - Mathematical model of segmentation in somitogenesis in vertebrates, Biophysics, 40 (1995), pp. 583-589.

[78] - Mathematical modelling of the mechanism of vertebrate somitic segmentation, J. Biol. Sys., 3 (1995), pp. 1041-1051.

[79] O. POURQUIÉ, Clocks regulating developmental processes, Curr. Opin. Neurobiol., 8 (1998), pp. 665-670.

[80] O. PourquiÉ, Notch around the clock, Curr. Opin. Gen. Dev., 9 (1999), pp. 559-565.

[81] D. R. N. Primmett, W. E. Norris, G. J. CARlson, R. J. Keynes, And C. D. Stern, Periodic segmental anomalies induced by heat shock in the chick embryo are associated with the cell cycle, Development (Cambridge), 105 (1989), pp. 119-130.

[82] D. R. N. PRimmetT, C. D. STERn, AND R. J. KeYNES, Heat shock causes repeated segmental anomalies in the chick embryo, Development (Cambridge), 104 (1988), pp. 331339.

[83] D. Psychoyos AND C. D. STERn, Fates and migratory routes of primitive streak cells in the chick embryo, Development (Cambridge), 122 (1996), p. 1523.

[84] - Restoration of the organizer after radical ablation of hensen's node and the anterior primitive streak in the chick embryo, Development, 122 (1996), pp. 3263-3273.

[85] G. L. Radice, H. Rayburn, H. Matsunami, K. A. Knudsen, M. Takeichi, and R. O. HYNES, Developmental defects in mouse embryos lacking $n$-Cadherin, Dev. Biol., 181 (1997), pp. 64-78.

[86] M. N. ROY, V. E. PRINCE, AND R. K. Ho, Heat shock produces periodic somitic disturbances in the zebra£sh embryo, Mech. Dev., 85 (1999), pp. 27-34.

[87] S. SCHNEll AND P. K. MAINI, Clock and induction model for somitogenesis, Dev. Dyn., 217 (2000), To appear.

[88] G. C. Schoenwolf, Cell movements in the epiblast during gastrulation and neuralation in avian embryoes, in Gastrulation, R. Keller, ed., Plenum Press, New York, NY, USA; London, UK, 1991, pp. 1-28.

[89] M. SELlECK AND C. STERn, Fate mapping and cell lineage analysis of hensen's node in the chick embryo, Development, 112 (1991), pp. 615-626.

[90] - Formation and Differentiation of Early Embryonic Mesoderm, Plenum Press, New York, 1992, ch. Evidence for stem cells in the mesoderm of Hensen's node and their role in embryonic pattern formation, pp. 23-31.

[91] S. B. Shah, I. Skromne, C. R. Hume, D. S. Kessler, K. J. Lee, C. D. Stern, And $\mathrm{J}$. DoDD, Misexpression of chick Vg1 in the marginal zone induces primitive streak formation, Development (Cambridge), 124 (1997), pp. 5127-5138. Department of Physiology and Cellular Biophysics, College of Physicians and Surgeons of Columbia University, New York, NY 10032, USA.

[92] J. M. W. SLACK, From Egg to Embryo. Regional speci£cation in early development, Cambridge: Cambridge University Press, 1991.

[93] N. SPRATT, Location of organ-specifc regions and their relationship to the development of the primitive streak in the early chick blastoderm, J. Exp. Zool., 89 (1942), pp. 69-101.

[94] - Regression and shortening of the primitive streak in the explanted chick blastoderm., J. Exp. Zool., 104 (1947), pp. 69-100. 
[95] - Some problems and principles of development, Am. Zool., 6 (1966), pp. 215-254

[96] N. SPRATT AND H. HAAS, Integrative mechanisms in development of the early chick blastoderm. I Regulative potentiality of separate parts, J. Exp. Zool., 145 (1960), pp. 97-137.

[97] C. Stern, Gastrulation: Movements, Patterns, and Molecules, Plenum, New York, 1991, ch. Mesodorm formation in the chick embryo revisited., pp. 29-41.

[98] C. STERN AND D. CANNING, Origin of cells giving rise to mesoderm and endoderm in the chick embryo., Nature, 343 (1990), pp. 273-275.

[99] C. D. STERN, The marginal zone and its contribution to the hypoblast and primitive streak of the chick embryo, Development (Cambridge), 109 (1990), p. 667.

[100] C. D. STERN AND R. BELLAIRS, Mitotic activity during somite segmentation in the early chick embryo, Anat. Embryol. (Berl.), 169 (1984), pp. 97-102.

[101] C. D. Stern, S. E. Fraser, R. J. Keynes, AND D. R. N. Primmett, A cell lineage analysis of segmentation in the chick embryo, Development (Cambridge), 104 Supplement (1988), pp. 231-244.

[102] A. Streit, K. LeE, I. Woo, C. Roberts, T. Jessell, And C. Stern, Chordin regulates primitive streak development and the stability of induced neural cells, but is not suffcient for neural induction in the chick embryo, Development, 125 (1998), pp. 507-519.

[103] D. Summerbell And M. Maden, Retinoic acid, a developmental signalling molecule, Trends in neurosciences (Regular ed.), 13 (1990), pp. 142-147.

[104] P. P. L. TAM AND P. A. TRAINOR, Specifcation and segmentation of the paraxial mesoderm, Anat. Embryol. (Berl.), 189 (1994), pp. 275-305.

[105] L. VAKAET, Chimeras in Developmental Biology, Academic Press, London, 1984, ch. Early development of birds.

[106] M. VEINI AND R. BELlAIRS, Somites in Developing Embryos, vol. 118 of NATO ASI series. Series A, Life sciences, New York: Plenum Press., 1986, ch. Heat shock effects in chick embryos, pp. 135-145.

[107] F. WACHTLET, B. Christ, AND H. J. JACOB, Grafting experiments on determination and migratory behaviour of presomitic, somitic and somatopleural cells in avian embryos, Anat. Embryol. (Berl.), 164 (1982), pp. 369-378.

[108] C. Waddington, Induction by the endodrem in birds., Roux's Arch. Dev. Biol., 128 (1933), pp. 502-521.

[109] Y. WEI AND T. MIKAWA, Formation of the avian primitive streak from spatially restricted blastoderm: evidence for polarized cell division in the elongating streak, Development, 127 (2000), pp. 87-96.

[110] R. G. Weisblat, C. J. Wedeen, And R. G. Kostriken, Evolution of developmental mechanisms: Spatial and temporal modes of rostrocaudal patterning, Curr. Top. Dev. Biol., 29 (1994), pp. 101-134.

[111] O. K. WILBY AND D. A. EDE, A model for generating the pattern of cartilage skeletal elements in the embryonic chick limb, Journal of Theoretical Biology, 52 (1975), pp. 199_ 217.

[112] S. YUAN, D. DARNELl, AND G. SCHOENWOLF, Identifcation of inducing, responding and supressing regions in an experimental model of notochord formation in avian embryos, Dev. Biol., 172 (1995), pp. 567-584.

[113] - Mesodermal patterning during avian gastrulation and neurulation: experimental induction of notochord from non-notochordal precursor cells, Dev. Genets., 17 (1995), pp. 38-54.

[114] S. YUAN AND G. SCHOENWOLF, De novo induction of the organizer and formation of the primitive streak in an experimental model of notochord reconstitution in avian embryos, Development, 125 (1998), pp. 201-213.

[115] - Reconstitution of the organizer is both suffcient and required to re-establish a fully patterned body plan in avian embryos, Development, 126 (1999), pp. 2461-22473.

[116] Y. P. YuAn, J. Schultz, M. MlodZIK, AND P. BORK, Secreted fringe-like signalling molecules may be glycosyl-transferases, Cell, 88 (1997), pp. 9-11.

[117] N. ZHANG AND T. GRIDLEY, Defect in somite formation in lunatic fringe-defcient mice, Nature, 394 (1998), pp. 374-377.

[118] T. ZIV, Y. SHIMONI, AND E. MitRANI, Activin can generate ectopic axial structures in chick 
blastoderm explants, Development, 115 (1992), pp. 689-694. 